\title{
EP-1151 Progesterone is a potent substance which inhibits the migration of ovarian cancer cells by reducing epithelial-mesenchymal transition via progesterone receptor-dependent pathway
}

So-Ye Jeon and Kyung-Chul Choi Correspondence

Laboratory of Biochemistry and Immunology, College of Veterinary Medicine, Chungbuk National University, Cheongju, Chungbuk 361-763 Republic of Korea

\section{ABSTRAC'T}

Ovarian carcinoma (OC) is the most deadly and leading cause of cancer death occurring in the female reproductive tracts. Several factors involved in ovarian carcinoma remain poorly defined and the therapy for $\mathrm{OC}$ is limited. Epidemiological data strongly suggest that endogenous and exogenous steroid hormones may play important roles in ovarian carcinogenesis. One of the primary steroid hormones, progesterone (P4), offers protection against ovarian carcinogenesis. We predicted that progesterone would inhibit the migration of BG-1 ovarian cancer cells by reducing epithelial-mesenchymal transition (EMT) as well as the growth of cancer cells. First, we investigated the expression of progesterone receptors in ovarian cancer cells with RT-PCR. Next, we determined a proper concentration of progesterone, 17ß-estradiol (E2; a positive control), and Mifepristone (anti-progesterone receptor agent) through MTT assay. We confirmed that progesterone reduced the ovarian cancer cell viability in a dose-dependent manner, which was inhibited by Mifepristone. Also, the migration of ovarian cancer cells was reduced by the treatment of progesterone in comparison with negative and positive control groups. Additionally, the alteration of EMT markers such as vimentin was examined at mRNA and protein levels by using reverse-transcription (RT)-PCR and western blot. The expression of Vimentin was reduced in the treatment of progesterone while the expression of its reverse transition marker E-cadherin was increased. These results indicate that progesterone can inhibit the migration of BG-1 ovarian cancer cells by reducing EMT. Further studies using in vivo xenografted mouse models will be needed to predict that progesterone significantly inhibits the growth of ovarian cancer without any virulent effects on the animals. Consequently, the present results represent that progesterone is a potent substance which inhibits the growth of human ovarian cancer cells and metastasis. Therefore, this hormone therapy may be a clinically effective tool for the treatment of human ovarian cancer.

\section{RESULT}
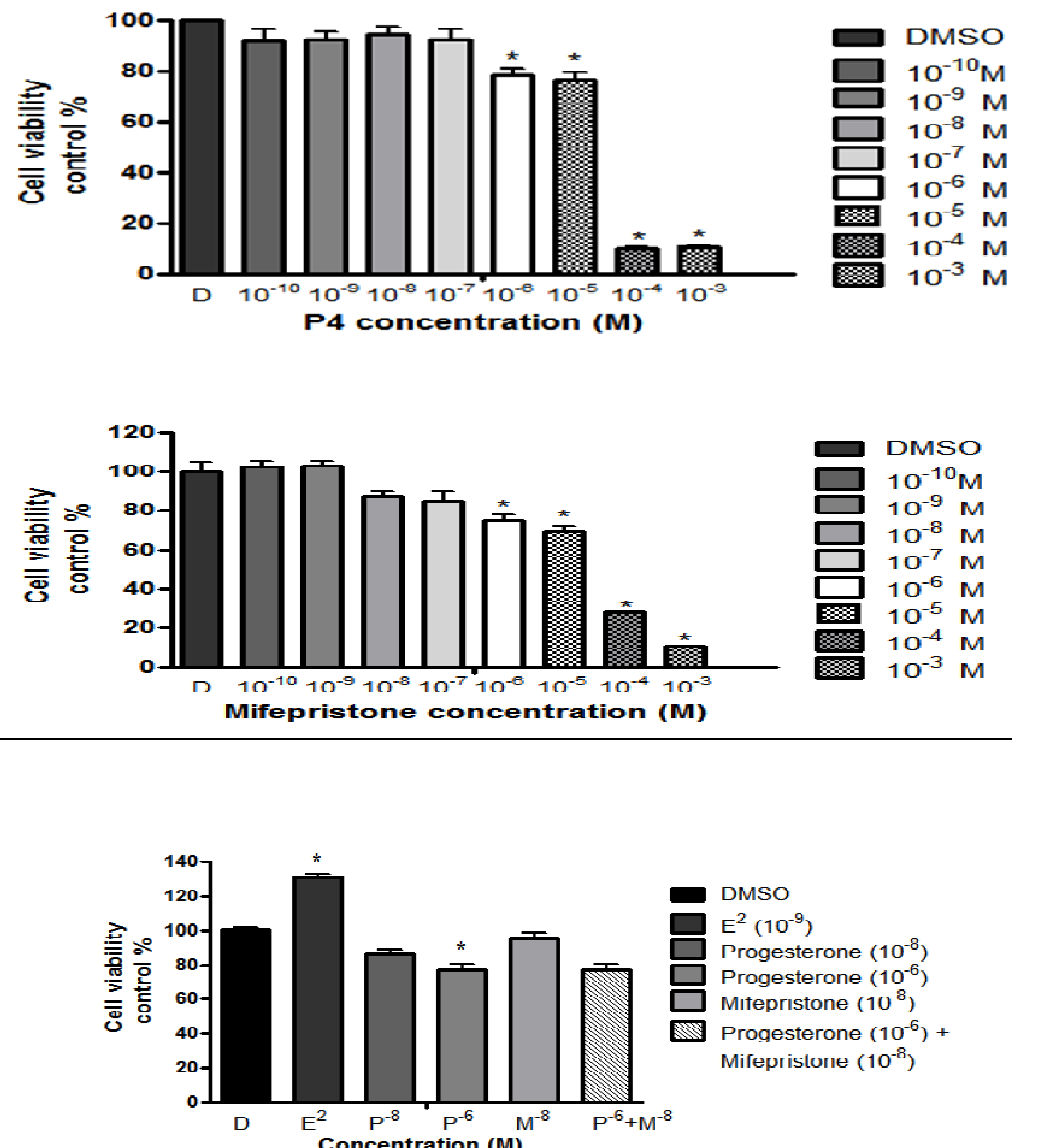

Figure 1. The effects of Progesterone, E2 and Mifepristone on cell proliferation of BG-1 cells. BG-1 cells were seeded at 5000 cells/well in 96-well plates in the presence of phenol redfree DMEM $(+5 \%$ CD-FBS $)$. After 2 days, the medium was replaced by phenol red-free DMEM $(+5 \%$ CD-FBS) containig (A) Progesterone, (B) Mifepristone, and (C) Progesterone, E2 and Mifepristone at the indicated concentration for 4 days. The cell viability was determined by MTT assay. * $\mathrm{P}<0.05$ compared to a vehicle treated with DMSO.

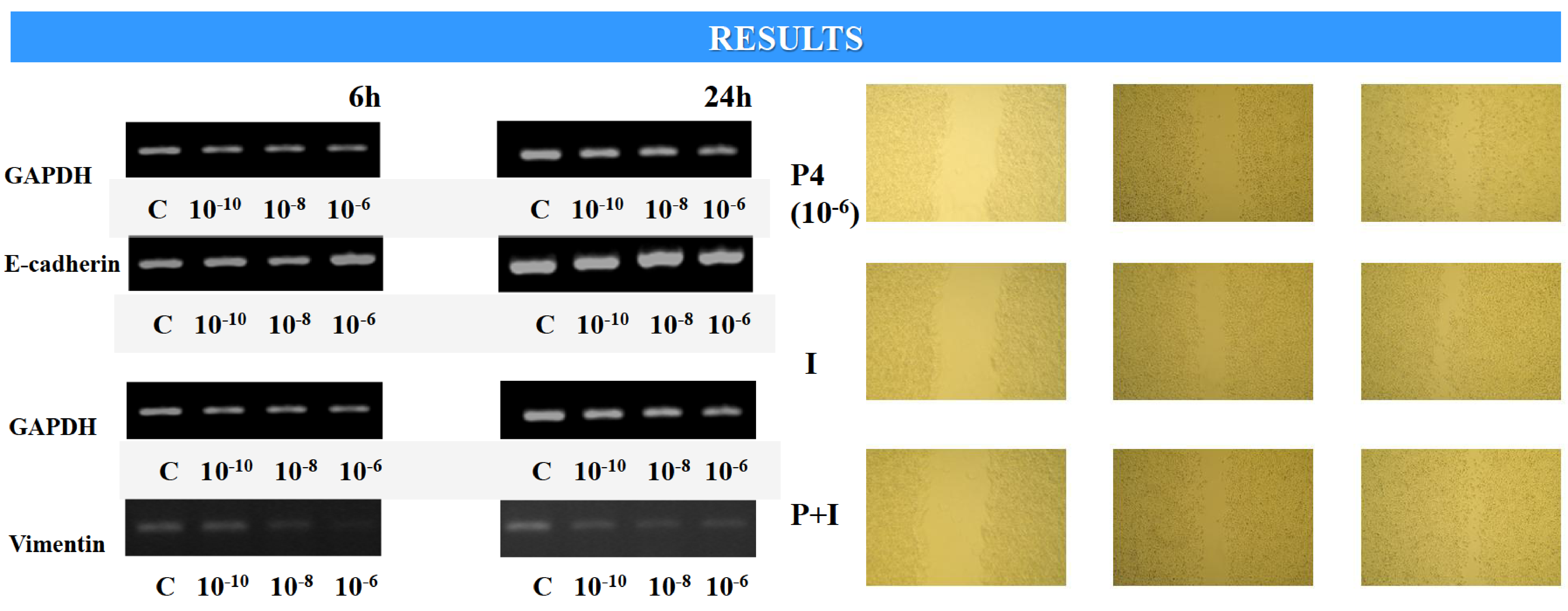

Figure 2. The effects of Progesterone on mRNA expression of Epithelial-mesenchymal transition related genes. BG- 1 cells were treated with $0.1 \%$ DMSO as a vehicle. The effects of Progesterone $\left(10^{-10} \mathrm{M}, 10^{-8} \mathrm{M}, 10^{-6}\right)$ was investigated on the expression of (A) E-cadherin, (B) Vimentin in BG-1 cells by RT-PCR. The products were seperated in a $1.5 \%$ agarose gel.

\section{4h}

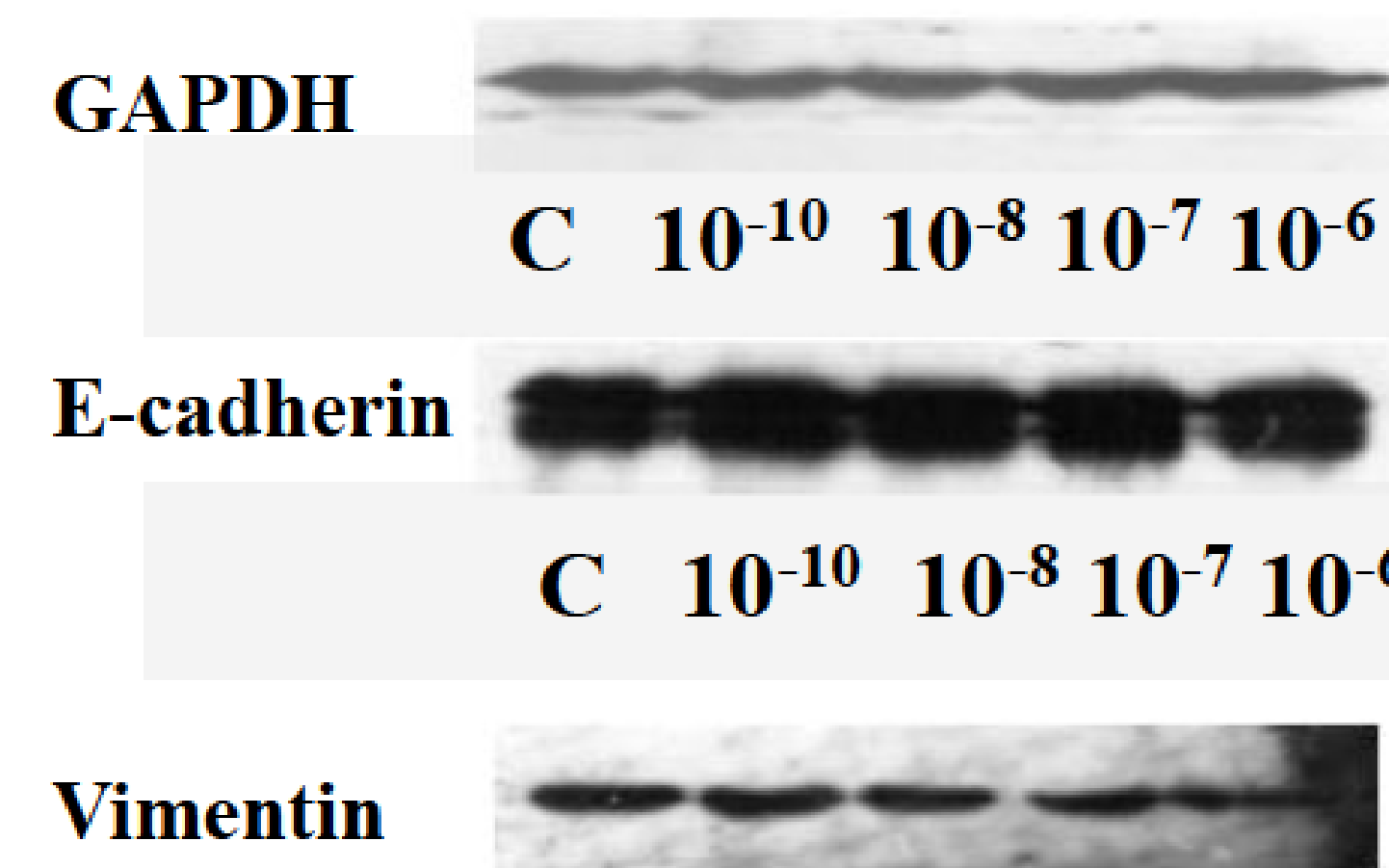

C $10^{-10} 10^{-8} 10^{-7} 10^{-6}$
$48 h$

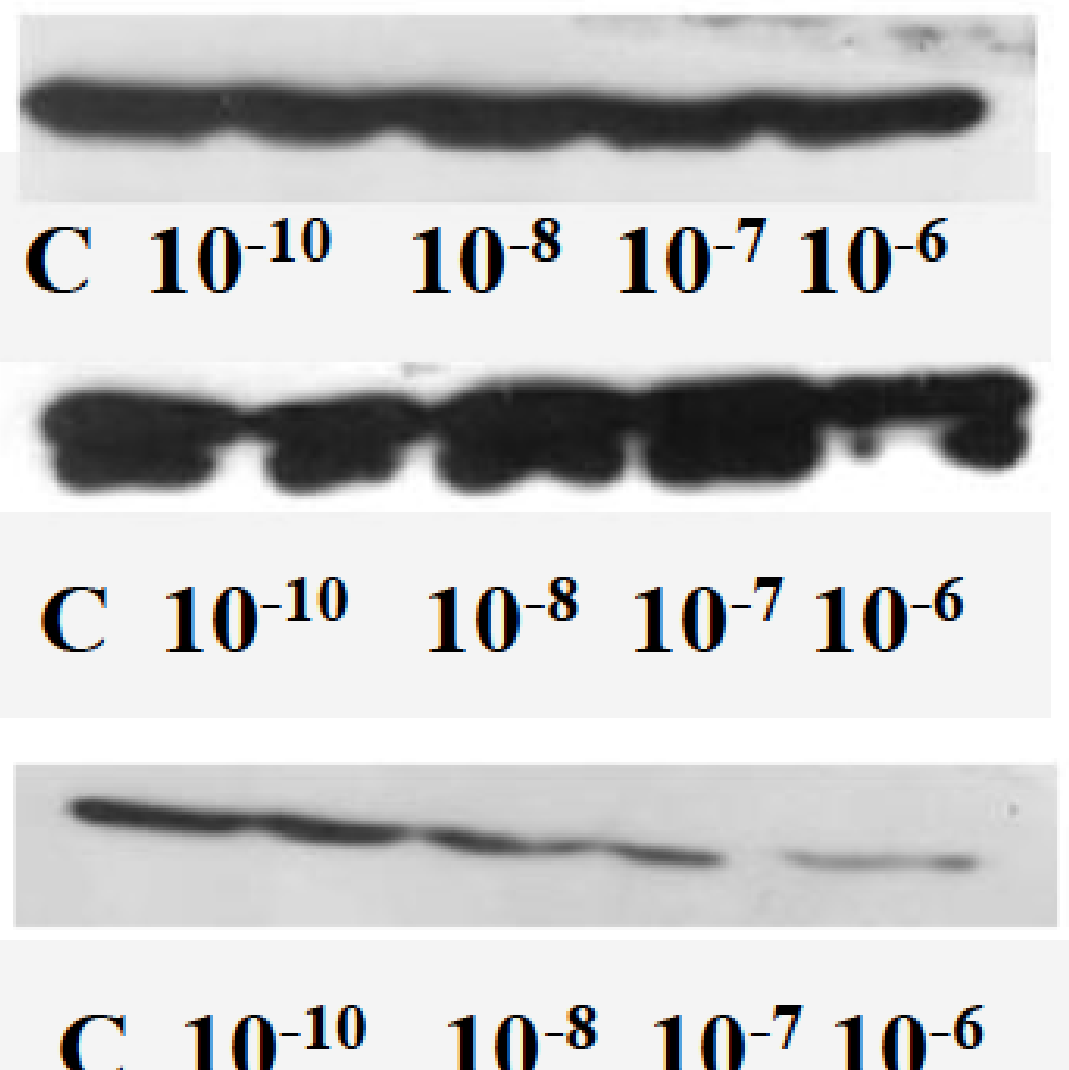

Figure 3. The effects of Progesterone on protein expression of Epithelial-mesenchymal transition related genes. BG-1 cells were treated with $0.1 \%$ DMSO as a vehicle. The effects of Progesterone $\left(10^{-10} \mathrm{M}, 10^{-8} \mathrm{M}, 10^{-7} \mathrm{M}, 10^{-6} \mathrm{M}\right)$ was investigated on the expression of E-cadherin and Vimentin in BG-1 cells by western blot.
$24 h$

GAPDH

E-cadherin

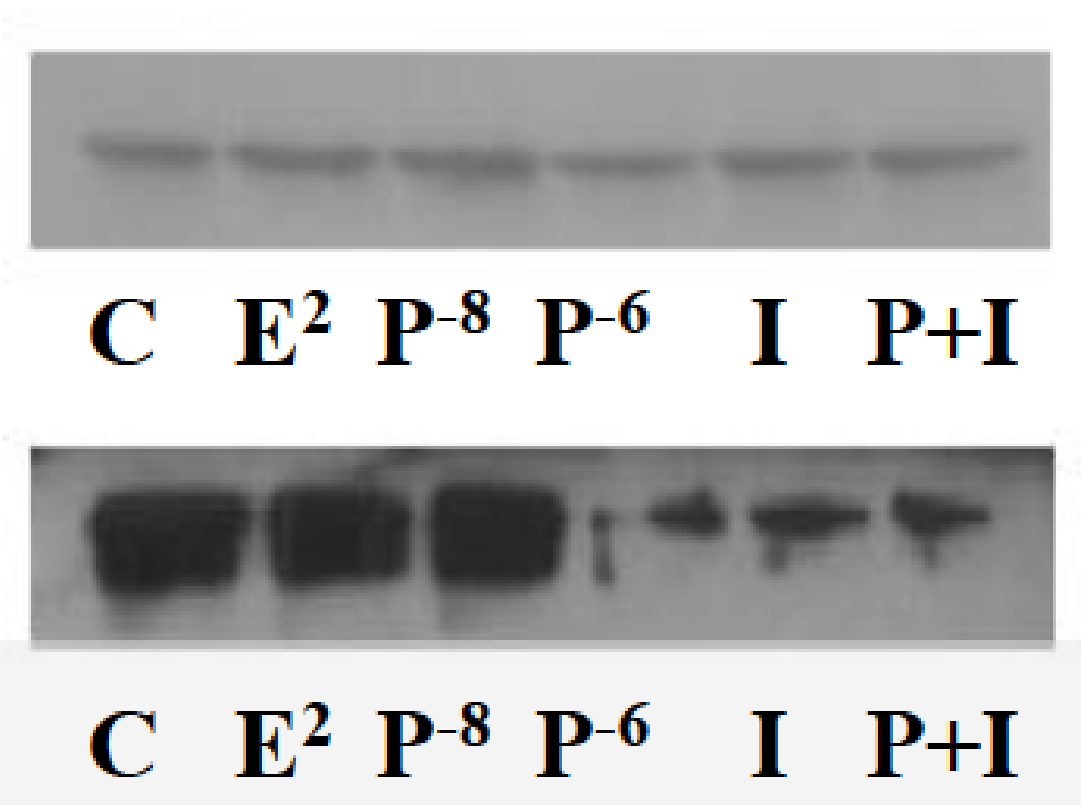

$48 h$

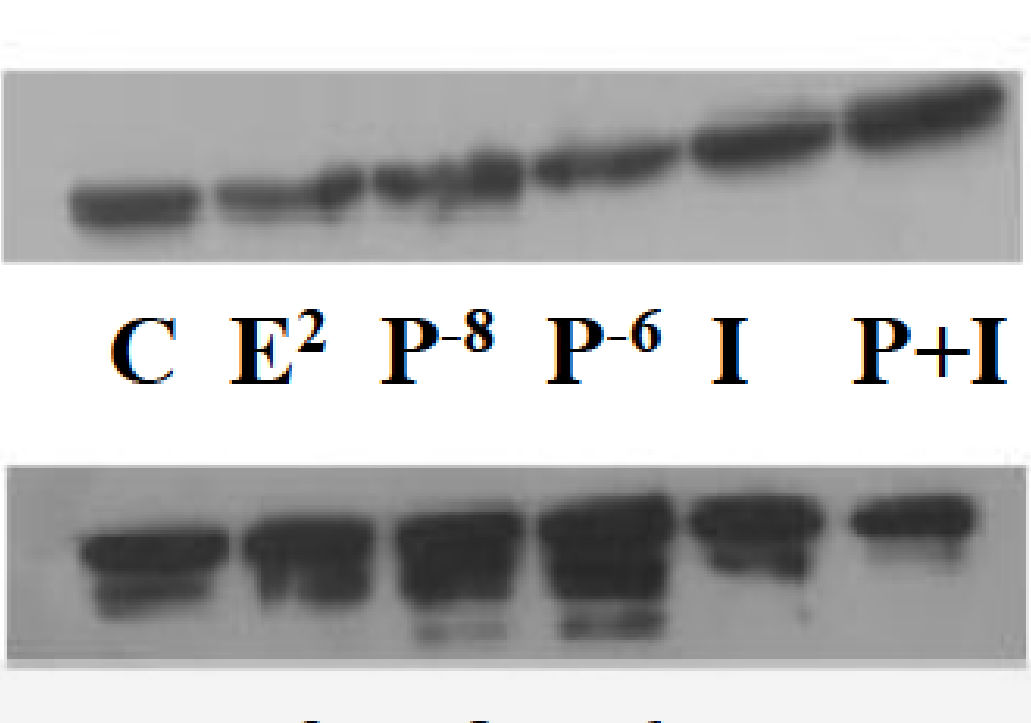

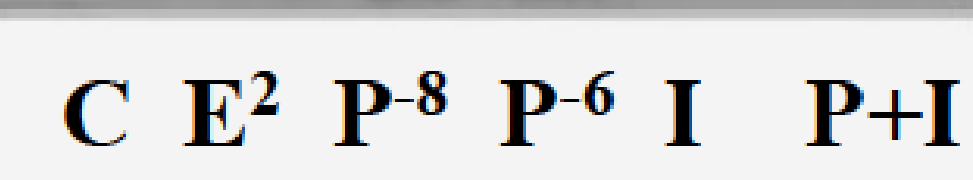

Figure 4. The effects of Progesterone on protein expression of Epithelial-mesenchymal transition related genes in the presence of anti-Progesterone receptor (Mifepristone). BG-1 cells were treated with $0.1 \%$ DMSO as a vehicle and $10^{-9} \mathrm{E} 2$ as a positive control. The effects of Progesterone $\left(10^{-8} \mathrm{M}, 10^{-6} \mathrm{M}\right)$, Mifepristone $\left(10^{-8} \mathrm{M}\right)$ was investigated on the expression of E-cadherin in BG-1 cells by western blot.

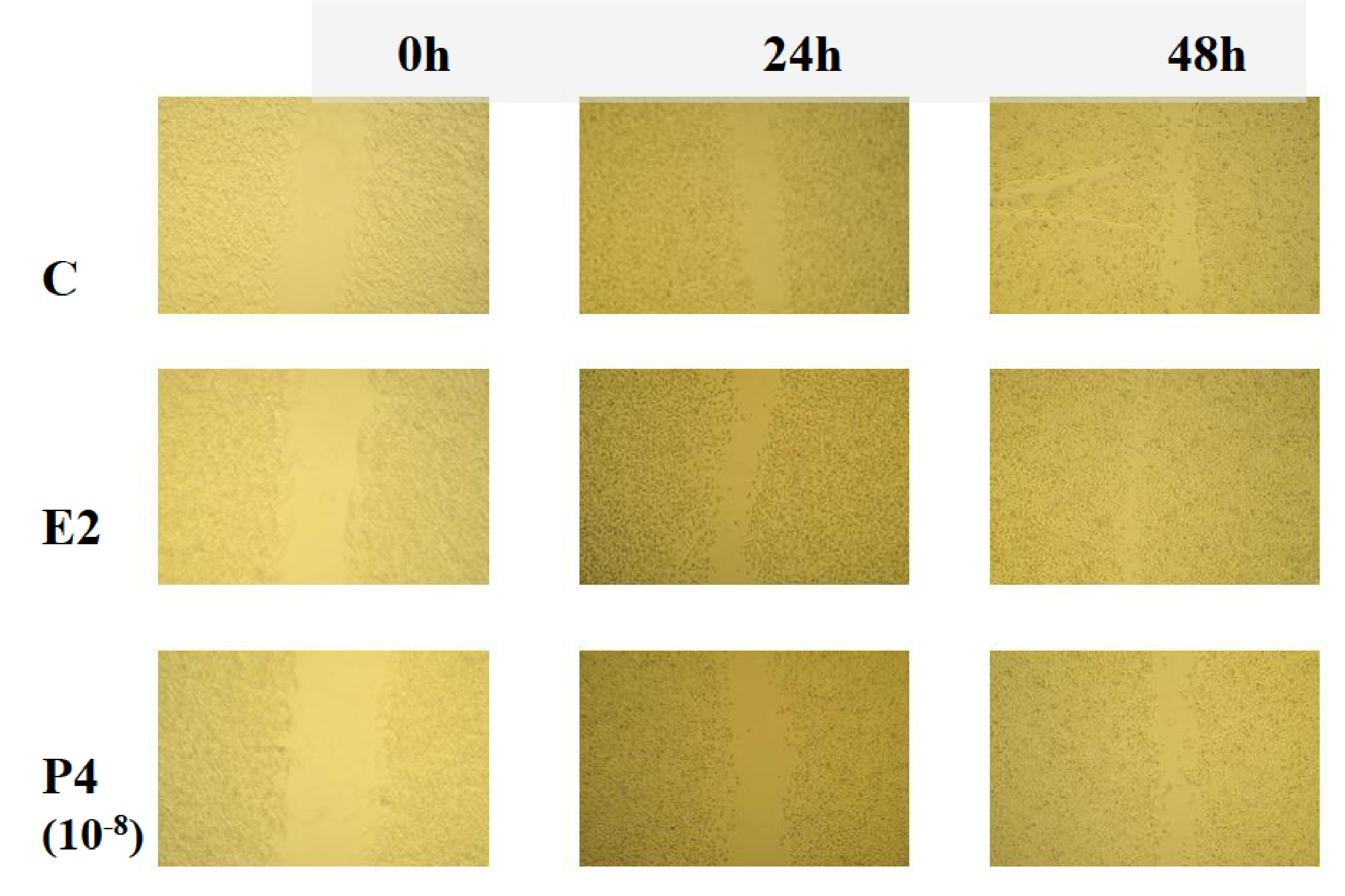

Figure 5. The effects of Progesterone, E2 and Mifepristone on BG-1 cell migration in a sacatch assay. BG- 1 cells were seeded at $0.4 \times 10^{6}$ cells/well in 6 -well plates and incubated for 2days with phenol redfree DMEM $(+5 \%$ CD-FBS $)$ before scratching with a $1 \mathrm{ml}$ pipette tip. Medium was replaced by phenol red-free DMEM (+10\% CD-FBS) containing DMSO (0.1\%), E2(10-9M), Progesterone (10-8M, 10-6M), Mifepristone $(10-8 \mathrm{M})$ as indicated for $0 \mathrm{~h}, 24 \mathrm{~h}$ and $48 \mathrm{~h}$. Images were captured at X40 maginification using an Olympus CKX 41 microscope.

\begin{tabular}{l} 
CONCLUSION \\
\hline In this study, we showed that Progesterone \\
reduced the ovarian cancer cell viability in a dose- \\
dependent manner, which was inhibited by \\
Mifepristone. The expression of Vimentin was \\
reduced in the treatment of progesterone while \\
the expression of its reverse transition marker E- \\
cadherin was increased. Also the wounded area \\
of BG-1 cell monolayers healed slowly in vehicle- \\
treated cells. On the contrary, in the presence of \\
Progesterone, the closure of the wounded gap was \\
significantly inhibited at $48 \mathrm{~h}$. These results \\
indicate that progesterone can inhibit the \\
migration of BG-1 ovarian cancer cells by \\
reducing EMT. Consequently, the present results \\
represent that progesterone is a potent substance \\
which inhibits the growth of human ovarian \\
cancer cells and metastasis.
\end{tabular}

\section{REFERENCES}

1. Logginidou H, Ao X, Russo I,Henske EP (2000) Frequent estrogen and progesterone receptor immunoreactivity in renal angiomyolipomas from women with pulmonary lymphangioleiomyomatosis. Chest 117(1):25-30

2. Ohori NP, Yousem SA, Sonmez-Alpan E, Colby TV (1991) Estrogen and progesterone receptors in lymphangioleiomyomatosis, epithelioid hemangioendothelioma, and sclerosing hemangioma of the lung. Am J Clin Pathol 96(4):529-535

3. Matsui K, Takeda K, Yu ZX, Valencia J, TravisWD, Moss J, Ferrans VJ (2000) Downregulation of estrogen and progesterone receptors in $t$ he abnormal smooth muscle cells i n pulmonary lymphangioleiomyomatosis following therapy. An immunohistochemical study. Am J Respir Crit Care Med 161(3 Pt 1):1002-1009

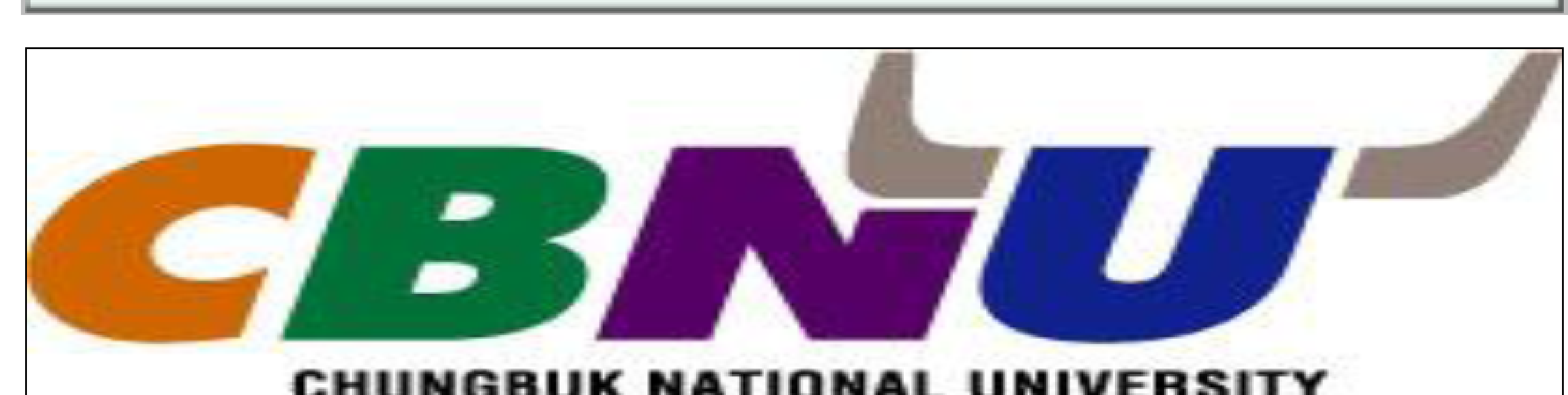

